\title{
An Oxygen Tracer Study of InP Oxidation
}

\author{
by \\ X. Liu, M.S. Denker and E.A. Irene \\ Department of Chemistry \\ University of North Carolina \\ Chapel Hill, NC 27599-3290
}

\begin{abstract}
The thermal oxidation process for InP results in a complex and process dependent oxide. From the observed self-limiting behavior of the oxide growth, the rate limiting step is likely the diffusion of reaction species through the growing oxide film. $\mathrm{O}^{18}$ marker oxidation experiments with the resulting secondary ion mass spectroscopy (SIMS) depth profiles reveal that the oxidation takes place at the oxide surface by the outward migration of In and $\mathrm{P}$, rather than at the oxide-substrate interface. Based on the available results possible models for the oxidation are proposed.
\end{abstract}

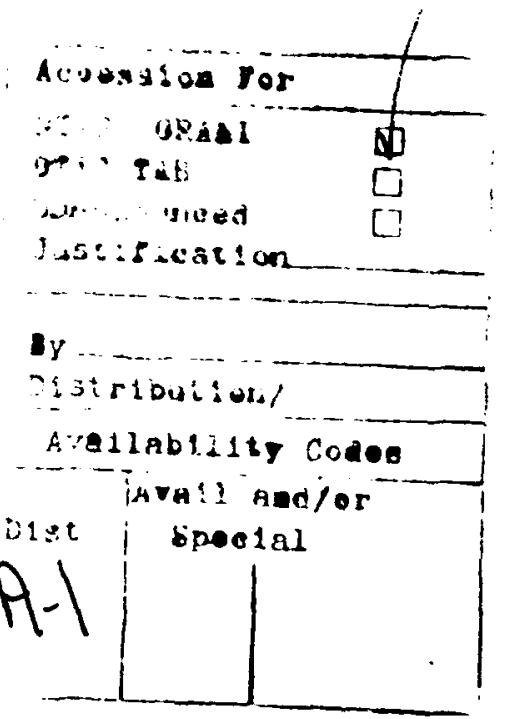




\section{Introduction}

InP continues to attract considerable research effort due to its direct band gap, high electron mobility and saturation velocity. Of great importance is the ability to fabricate Metal-Insulator-Semiconductor Field-Effect-Transistors, MISFETs, starting with InP and oxides grown thereon ${ }^{1,2,3,4}$. The thermal oxide grown on InP has been widely studied ${ }^{5,6,7,8,9,10}$ in an attempt to optimize MISFET's. However, the chemical composition of the oxide has been found ${ }^{11,12}$ to be both complicated and process dependent. Although some questions still remain, it is generally accepted that the oxide grown at low temperature $\left(\mathrm{T}<600^{\circ} \mathrm{C}\right)$ is composed of two layers of differing chemical composition: an In-rich outer layer of a mixture of $\operatorname{In}_{2} \mathrm{O}_{3}$ and $\mathrm{InPO}_{4}$ and an inner layer of predominantly $\mathrm{InPO}_{4}{ }^{13,14,15}$. Nelson et. al. ${ }^{15}$ has proposed an oxide growth model in which phosphorus $(\mathrm{P})$ and indium(In) diffuse outward through the existing initial oxide and react with oxygen at oxide surface. At lower temperature $\left(T<600^{\circ}\right), P$ diffuses slower than In, and thus piles up at the oxide-substrate interface resulting in an In rich oxide layer at the oxide surface. As predicted by the In-P-O phase diagram ${ }^{16} \mathrm{InPO}_{4}$ is the thermodynamically favored product hence the initial oxide is mainly $\mathrm{InPO}_{4}$ in composition. At higher temperature $\left(T>600^{\circ}\right)$, where the diffusion rate for both In and $\mathrm{P}$ is greatly accelerated and therefore no longer rate limiting, only $\mathrm{InPO}_{4}$ is formed. This model agrees with much of the available data, however, direct verification is still lacking.

In the present research it is found that the thermal oxidation is self-limiting at oxidation temperatures less than $500^{\circ} \mathrm{C}$, which suggests that diffusion is the rate limiting step for the InP oxidation. $\mathrm{O}^{18}$ marker oxidation experiments have been carried out to identify the 
majority diffusion species. The resulting secondary ion mass spectroscopy(SIMS) depth profiles reveal that the oxidation takes place at the oxide surface rather than at the oxidesubstrate interface. Based on the $\mathrm{O}^{18}$ marker experiments, a thermal oxidation model for InP at low temperatures $\left(T<500^{\circ} \mathrm{C}\right)$ has been proposed.

\section{Experimental procedures}

N-type undoped (100) oriented InP $\left(n<1.0 \times 10^{16} \mathrm{~cm}^{-3}\right)$ wafers were cut into $1 \mathrm{~cm} \times 1 \mathrm{~cm}$ samples. The thermal oxidations used for obtaining the growth rate were performed in a conventional horizontal fused silica tube inside a resistance heated furnace. The samples were chemically cleaned ${ }^{17}$, and loaded onto a fused silica boat. The boat was then placed in the end cap of the furnace tube for further drying, pushed into the hot zone in a $\mathrm{N}_{2}$ atmosphere for a 15 minute pre-oxidation annealing at the temperature of the oxidation, and then oxidized in $1 \mathrm{~atm} \mathrm{O}_{2}$ for the desired time, and finally cooled in $\mathrm{N}_{2}$. The $\mathrm{O}^{18}$ marker oxidation experiments were performed in a small fused silica furnace tube that could be sealed and pumped to below $10^{-3}$ torr. A gas manifold enabled the switching of gases $\left(\mathrm{N}_{2}\right.$, normal $\mathrm{O}_{2}, \mathrm{O}_{2}{ }^{18}$ enriched) during an oxidation without exposing the samples to the outside air and a similar cleaning and oxidation procedure as above was used. The oxide samples were stored in a $\mathrm{N}_{2}$ box usually overnight for SIMS analysis.

The SIMS depth profiles of the $\mathrm{O}^{18}$ marked oxide were performed on a Perkin Elmer PHI6300 SIMS system. $\mathrm{A} \mathrm{Cs}^{+}$ion source was used as the primary sputtering beam, and base pressure was about $5 \times 10^{-10}$ torr. Since the sputtering yield for $\mathrm{InP}$ oxide is high, a low beam current is necessary to obtain adequate depth resolution ${ }^{18}$. A $5 \mathrm{KV}, 10 \mathrm{nA}$ primary 
beam was used, and the incident angle of the beam was set to $60^{\circ}$ resulting in a sputtering rate of approximately $50 \AA / \mathrm{min}$.

\section{Results and Discussion}

The oxidation of $\operatorname{InP}$ has been found ${ }^{8,19}$ to be slow at $340^{\circ} \mathrm{C}$, but increases rapidly with temperature, and the oxide film growth rate is initially fast but saturates quickly yielding self-limiting growth. We performed a variety of thermal oxidations of InP in $\mathrm{O}_{2}$ up to $500^{\circ} \mathrm{C}$ and analyzed the grown oxide using ellipsometry and with optical properties for the oxide and substrate that were previously measured ${ }^{14,17}$. Figure 1 shows our typical results that indicate self limiting growth hence a diffusional rate limiting mechanism in substantial agreement with the previous workers.

The complex oxide structure found by many workers makes the assignment of a simple mechanism dubious ${ }^{20}$. In order to address this issue we used an $\mathrm{O}^{18}$ isotope marker oxidation experiment in which an oxide film is first grown in an $\mathrm{O}_{2}{ }^{16}$ ambient (natural abundance), and then for some samples the oxidation ambient is switched to an $\mathrm{O}_{2}{ }^{18}$ enriched ambient for further oxidation at the same temperature. The $\mathrm{O}^{16}$ and $\mathrm{O}^{18}$ depth profiles are then measured using SIMS and the location of the $\mathrm{O}^{18}$ peak can be used to deduce the predominant diffusion mechanism.

Figure 2a shows the SIMS depth profiles for an oxide grown in $\mathrm{O}_{2}{ }^{16}$ for 2 hours at $450^{\circ} \mathrm{C}$. The ion counts for In are constant through the oxide layer and increase slightly at the oxide-InP interface. If the oxide interface is located where the ion counts is one half of the maximum ${ }^{21}$, then the interface is near 9 minutes sputtering time. The oxide interface is 
also indicated by the $\mathrm{O}^{16}$ and $\mathrm{O}^{18}$ profiles, as the counts drop more than 3 orders from the oxide layer to the substrate. Since no $\mathrm{O}^{18}$ was introduced during the oxidation of the sample, the ratio of the $\mathrm{O}^{18}$ to $\mathrm{O}^{16}$ counts should be representative of the natural abundance of about $500: 1$, but it is found to be closer to $300: 1$ and likely due to the ion yield differences. The steady increase of the phosphorus counts in the oxide layer is consistent with the reports in the literature ${ }^{14,15}$ that show a P rich inner layer, and an In rich outer layer. However, the SIMS data do not show an abrupt interface between the two oxide layers, but this is not surprising, since the energetic bombardment used in the SIMS analysis causes ion mixing ${ }^{22}$.

The SIMS depth profiles shown in Fig. $2 b$ are for oxide samples grown in the same batch as those used for Fig. $2 \mathrm{a}$ and then received an additional $\mathrm{O}^{18}$ oxidation for 2 hours. Although the oxide is slightly thicker than that of the $0^{16}$ oxidation only (about $475 \AA$ rather than $450 \AA$ ), the $\mathrm{O}^{16}$ and In profiles are similar to those in Fig. 2a. However, the P profile shows a small plateau between a short initial rise and a long steady rise in the oxide layer. The initial rise is likely due to either a surface measurement artifact or a real deficit of phosphorus near the surface, and the plateau suggests that a uniform oxide with an abrupt boundary exists in the oxide layer near the surface. The difference in phosphorus profiles in Figs. $2 \mathrm{a}$ and $\mathrm{b}$ indicates that the chemical composition of the oxide varies with the oxidation time, which is consistent with Nelson's model ${ }^{15}$. However, our SIMS profile of phosphorus does not show a pile up at the oxide-InP interface as was reported in the literature ${ }^{5,7,8}$. This is not necessarily a disagreement with previous results ${ }^{15}$, since SIMS is a technique that detects the secondary ions emitted from a sample by ion bombardment, and the detected ions include contributions from all the oxidation states of the element. SIMS cannot distinguish 
elemental phosphorus from a phosphorus oxide nor from InP. The $P$ ion counts in the InP matrix $\left(2 \times 10^{4}\right)$ are sufficiently high to conceal the response of a possible $\mathrm{P}$ excess at the interface. The additional oxidation in $\mathrm{O}^{18}$ of the InP oxide results in a localized $\mathrm{O}^{18}$ distribution. The $\mathrm{O}^{18}$ profile in Fig. $2 \mathrm{~b}$ shows a peak near the oxide surface. The location of the excess $\mathrm{O}^{18}$ can best be represented by eliminating instrumental factors, which can be achieved by ratioing the relevant $\mathrm{O}^{18}$ profile over a matrix profile shown. Since the phosphorus profile varies and the indium counts are too low, the $\mathrm{O}^{16}$ profile is chosen as the reference, and this has the added advantage that the ratio of $\mathrm{O}^{18}$ to $\mathrm{O}^{16}$ is specifically interesting herein. This ratios of $\mathrm{O}^{18}$ to $\mathrm{O}^{16}$ counts for the oxides with and without $\mathrm{O}^{18}$ post oxidation are shown in Fig. 3. It is clear that the $\mathrm{O}^{18}$ is localized near the oxide surface indicating that the oxidation occurs at this surface. The slight rise of the ratio after about 12 minutes of sputtering is due to the fact that the detection limit for $\mathrm{O}^{18}$ has been reached. It is worth mentioning that the $\mathrm{O}^{16}$ predominates near the surface region, although the $\mathrm{O}^{18}$ counts are about an order higher there than in the bulk oxide. The predominance of the $\mathrm{O}^{16}$ near the

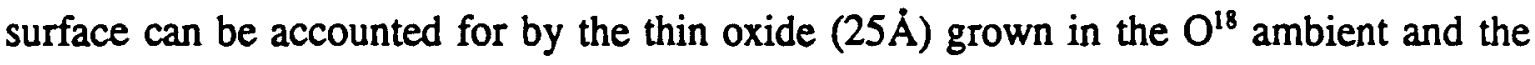
limited $\mathrm{O}^{18}$ available in the closed tube oxidation environment. The possible evaporation of $\mathrm{P}_{2} \mathrm{O}_{5}$ formed at the oxide surface, which will be discussed later, may account for some of the $\mathrm{O}^{18}$ loss.

The $\mathrm{O}^{18}$ marker experiments confirm that oxygen is not the diffusing species during oxidation in agreement with Nelson's model ${ }^{15}$. Furthermore, the oxidation reaction takes place at the outer interface. In Nelson's model, the migrating species are assumed to be In and $\mathrm{P}$ from the decomposition of the substrate, with In having a higher diffusion rate than $\mathrm{P}$. 
This would result in some elemental $P$ at the oxide-InP interface ${ }^{15}$. This explanation is consistent with our results if an appropriate diffusing species is considered. It may not be realistic to assume that In atoms diffuse faster than $\mathrm{P}$ atoms, since the atomic radii for In and $\mathrm{P}$ are $1.6 \AA$ and $1.1 \AA$, respectively ${ }^{23}$. If In and $\mathrm{P}$ are in the forms of $\mathrm{In}^{+3}$ and $\mathrm{P}^{+5}$, as from In $\mathrm{PO}_{4}$, the $\mathrm{In}^{+3}$ should diffuse more slowly than $\mathrm{P}^{+5}$, since the ionic radii are $0.8 \AA$ and $0.34 \AA$, respectively. Thus there are two remaining possibilities. One is that the $\mathrm{P}$ diffuses as $\mathrm{P}^{-3}$ and $\mathrm{In}$ as $\mathrm{In}^{+3}$ with ionic radii of $2.1 \AA$ and $0.8 \AA$, respectively and these species derive from the substrate InP. It may be improbable that phosphorus diffuses through the oxide network as $\mathrm{P}^{-3}$ both due to the strong reducing power of the ion and the fact that InP exhibits a small dissociation pressure at $700^{\circ} \mathrm{C}$ of less than $0.002 \mathrm{~mm} \mathrm{Hg}^{24}$, and of course far less near $500^{\circ} \mathrm{C}$. In addition, it is found that the annealing of oxide on InP in $\mathrm{N}_{2}$ ambient at $350^{\circ} \mathrm{C}$ does not result in the buildup of elemental phosphorus at the oxide-InP interface ${ }^{13}$. Furthermore, even if the dissociation of InP at the interface is the oxidation rate limiting step, the self-limiting growth behavior can not be explained since the supply of In and $P$ would continue. Finally, the phosphorus losses, probably by the evaporation of the $\mathrm{P}$ and $\mathrm{P}_{2} \mathrm{O}_{5}$ after phosphorus reaches the oxide surface, are found to be significant ${ }^{13}$ and are not accounted for in the Nelson model. A reasonable alternative can be obtained from a consideration that the overall oxidation consists of two oxidation reactions, one initially at the oxide-InP interface and the other at the oxide surface as illustrated in Fig. 4. First it is assumed that the oxidation takes place initially at the bare InP surface as:

$$
\mathrm{InP}+\mathrm{O}_{2}=\mathrm{InPO}_{4}
$$

As the $\mathrm{InPO}_{4}$ thickens, the diffusion flux of the oxidant species through the oxide layer 
decreases. Accordingly, compctitive processes become dominant. At the oxide-InP interface, there is a chemical equilibrium established:

$$
2 \mathrm{InPO}_{4}=\mathrm{In}_{2} \mathrm{O}_{3}+\mathrm{P}_{2} \mathrm{O}_{5}
$$

which will shift to the right if $\mathrm{P}_{2} \mathrm{O}_{5}$ is consumed leaving an $\mathrm{In}_{2} \mathrm{O}_{3}$ layer with a gradient of $P$ towards the oxide surface. A possible pathway, that is consistent with the phase diagram (16), that produces elemental phosphorus and $\mathrm{In}_{2} \mathrm{O}_{3}$ at the oxide-InP interface is:

$$
5 \mathrm{InP}+4 \mathrm{P}_{2} \mathrm{O}_{5}=5 \mathrm{InPO}_{4}+8 \mathrm{P}
$$

The resulting $\mathrm{P}$ and $\operatorname{In}_{2} \mathrm{O}_{3}$ could then supply the diffusion species with radii in the proper order: $\mathrm{P}^{\circ}(1.1 \AA)$ and $\operatorname{In}^{+3}(0.8 \AA)$. It should be mentioned that diffusion mechanisms do not always follow from ionic or atomic sizes. However, a plausible mechanism in accord with the relative sizes for diffusing species is a worthwhile starting point. The phosphorus atoms that diffuse through the oxide are then oxidized at the oxide surface and some can evaporate probably as $\mathrm{P}_{2} \mathrm{O}_{5}$. Therefore, the diffusion rate of $\mathrm{P}$ limits the oxide growth rate and the deficit of phosphorus near the oxide surface is the cause of the In rich outer oxide layer. Even this more complicated alternative model does not consider other possible oxide components, such as $\operatorname{In}\left(\mathrm{PO}_{3}\right)_{3}$ and $\mathrm{P}_{2} \mathrm{O}_{3}$. Nevertheless, the alternative model better fits the experimental observations. Further quantitative exneriments will be required to discriminate among the remaining possible models.

\section{Acknowledgement}

The authors gratefully acknowledge helpful discussions with Prof. J. Joseph of Ecole Centrale de Lyon and Dr. M. A. Ray of MCNC, and the use of the SIMS facility at MCNC 
by Dr. G. McGuire. This work was supported in part by the Office of Naval Research, ONR. 


\section{List of Figures}

Figure 1. Representative oxide thickness versus oxidation data for InP oxidation in $\mathrm{O}_{2}$ at $360^{\circ} \mathrm{C}$.

Figure 2. Secondary Ion Mass Spectroscopy depth profiles of thermal oxide on InP: a) for oxidation at $450^{\circ} \mathrm{C}$ for $2 \mathrm{hrs}$ in $\mathrm{O}_{2}{ }^{16}$ natural abundance and b) for the same as a) then followed by $2 \mathrm{hrs}$ in $\mathrm{O}_{2}{ }^{18}$ enriched oxygen.

Figure 3. Ratio of $\mathrm{O}^{18} / \mathrm{O}^{16}$ for thermal oxides grown on InP at $450^{\circ} \mathrm{C}$ in $\mathrm{C}_{2}{ }^{16}$ natural abundance (lower curve) and in $\mathrm{O}_{2}{ }^{16}$ followed by $\mathrm{O}_{2}{ }^{18}$ oxidation (upper curve).

Figure 4. Oxidation Model for InP thermal oxidation yielding a two layer oxide by the differential migration of In (faster) and $\mathrm{P}$ (slower) species. 
References

1. A. Falcou, G. Post, P. Viktorovitch, R. Blanchet, K. Choujaa, G. Hollinger, $Y$. Robach, and J. Joseph, Proceedings 1st. Int'I Conference InP \& Related Materials, 1144 (1989).

2. L.G. Meiners, D.L. Lile, and D.A. Collins, J. Vac. Sci. Technol., 16, 1458 (1979).

3. T. Sawada, A. Itagaki, H. Hasegawa, and H. Ohno, IEEE Trans. Elect. Dev. ED-31, 1038 (1984).

4. K.V. Klitzing, Th. Englert, and D. Fritzsche, J. Appl. Phys., 51, $5893(1980)$.

5. c.W. Wilmsen, Thin solid Films, 39, 105 (1976).

6. G. Hughes and R. Ludeke, J. Vac. Sci. Technol., B4, 1109 (1986).

7. G.P. Schwartz, W.A. Sunder, and J.E. Griffiths, Appl. Phys. Lett. 37,925 (1980).

8. J.F. Wager and C.W. Wilmsen, J. Appl. Phys., 51, 812 (1980).

9. O.R. Monteiro and J. W. Evans, J. Electrochem. Soc., 135, 2366 (1988).

10. Y. Robach, A. Gagnaire, J. Joseph, E. Bergignat, and G.Hollinger, Thin Solid Films, 162, 81 (1988).

11. J.F. Wager, D.I. Ellsworth, S.M. Goodnick, and C.W. Wilmsen, J. Vac. Sci. Technol., 19, 513 (1981).

12. C.W. Wilmsen, K.M. Geib, R. Gann, J. Costello, G.

Hryckowian, and R.J. Zeto, J. Vac. Sci. Technol., B3, 1103 (1985).

13. E. Bergignat, G. Hollinger, and Y. Robach, Surf. Sci., $189 / 190,353(1987)$.

14. X. Liu, J.W. Andrews, and E.A. Irene, J. Electrochem. Soc., 138, 1106 (1991).

15. A. Nelson, K. Geib, And C.W. Wilmsen, J. Appl. Phys., 54, 4134 (1983). 
16. G.P. Schwartz, W.A. Sundet and J.E. Griffiths, J. Electrochem. Soc., 129, 1361 (1982).

17. X. Liu, E.A. Irene, S. Hattangady, and G. Fountain, J. Electrochem. Soc., 137, 2319 (1990).

18. R.G. Wilson, F.A. Stevie, C.W. Magee, Secondary Ion Mass Spectrometry, Chapter 2, John Wiley \& Sons, (1989).

19. M.M. Moleshi and K. Saraswat, IEEE Trans. Elec. Dev., ED-32, $106(1985)$.

20. Y. Robach, A. Gagnaire, J. Joseph, E. Bergignat, and G. Hollinger, Thin Solid Films, 162, 81 (1988).

21. C.W. Magee, R.E. Honig, and C.A. Evans, Jr., in Secondary Ion Mass spectrometry SIMS III, edited by A. Benninghoven, J. Giber, J . Laszlo, M. Riedel, and H.W. Werner, Springer-Verlag, 172 (1981).

22. R.G. Wilson, F.A. Stevie, C.W. Magee, Secondary Ion Mass Spectrometry, Chapter 1, John Wiley\&Sons, (1989).

23. L. Pauling, The Nature of the Chemical Bond, 3rd. ed., Ithaca, New York, Cornell University Press, 1960.

24. K. Weiser, J. Phys. Chem., 61, 513(1957). 


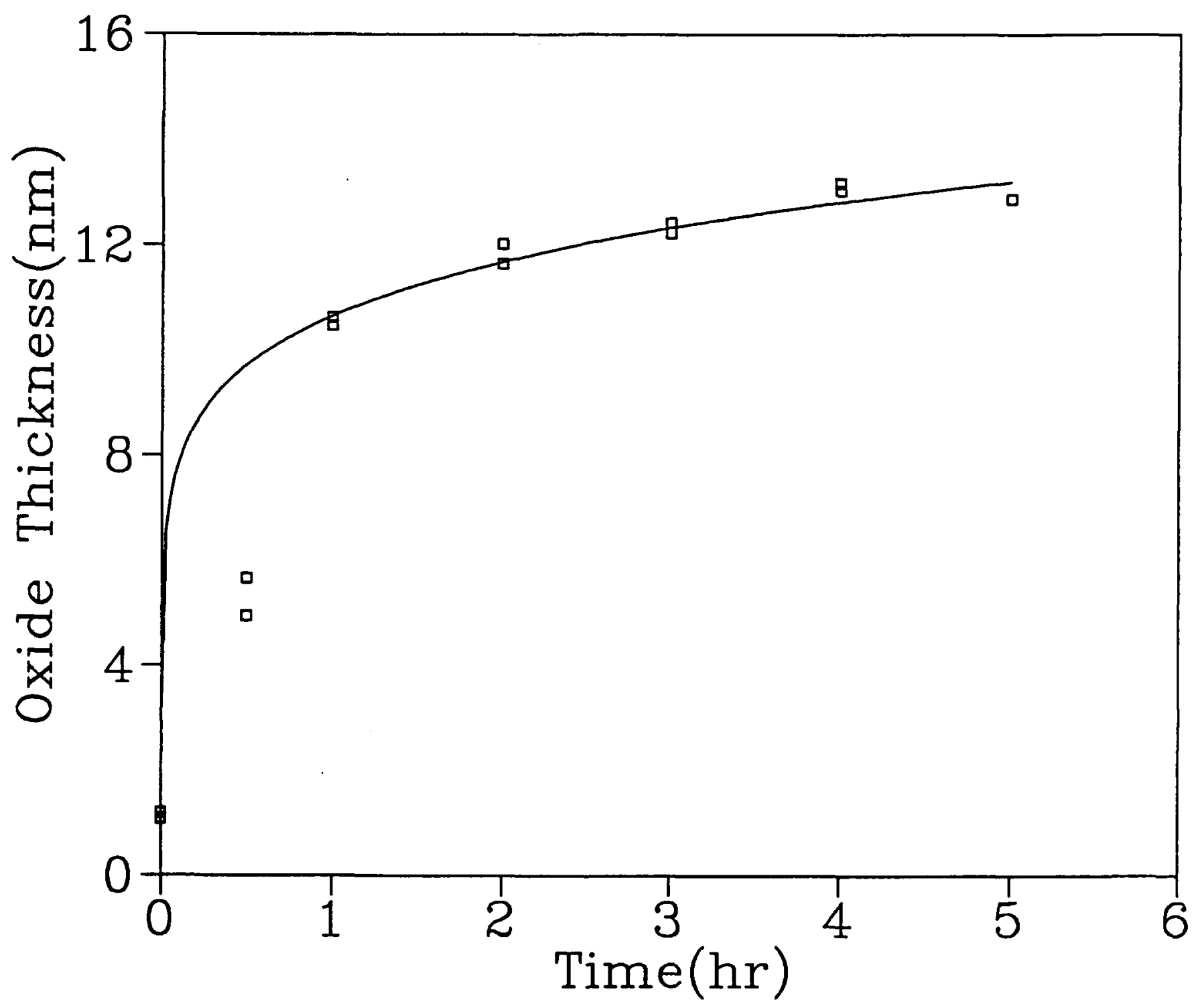

Fig 1. 


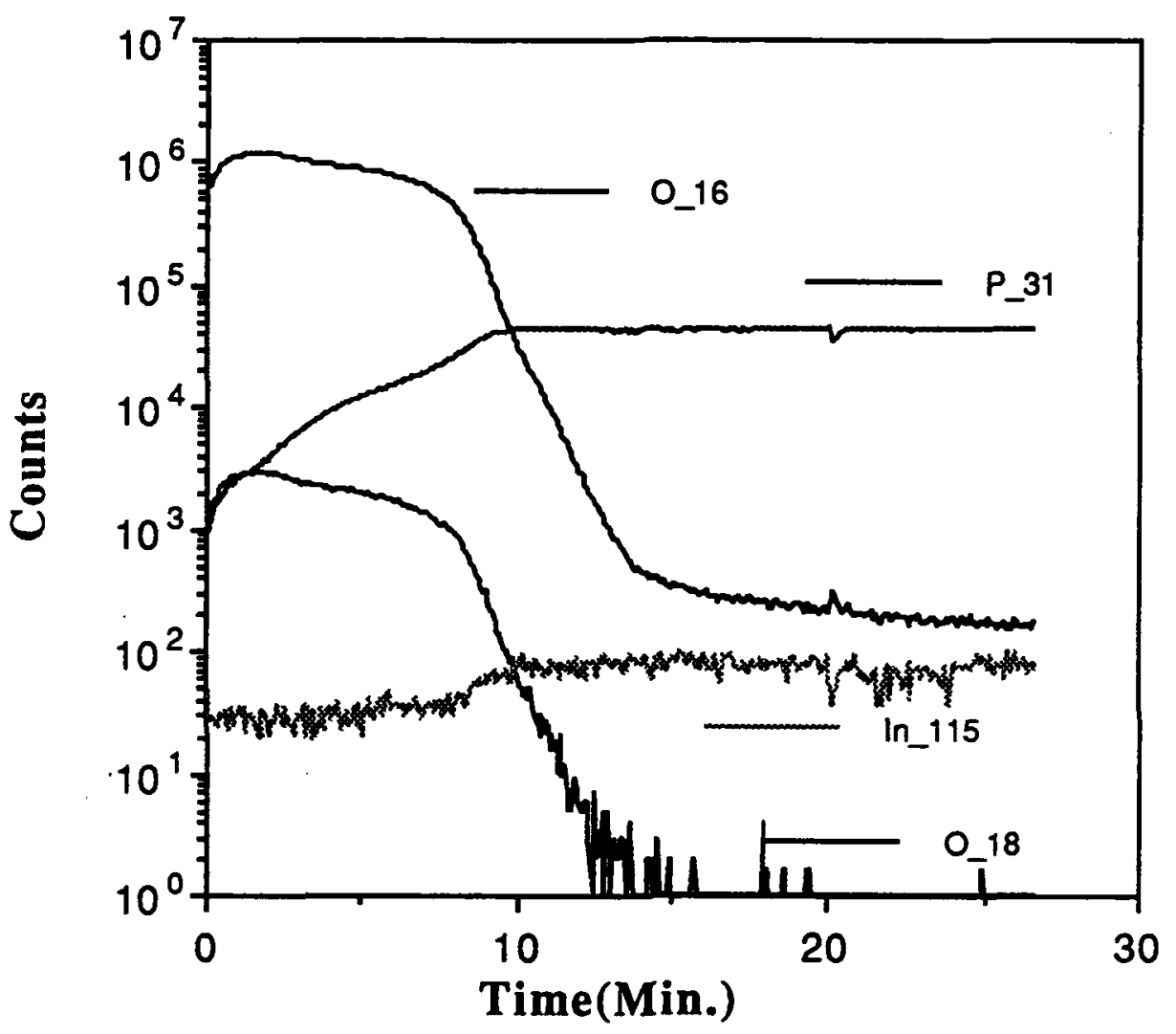

Fig. $2 a$ 


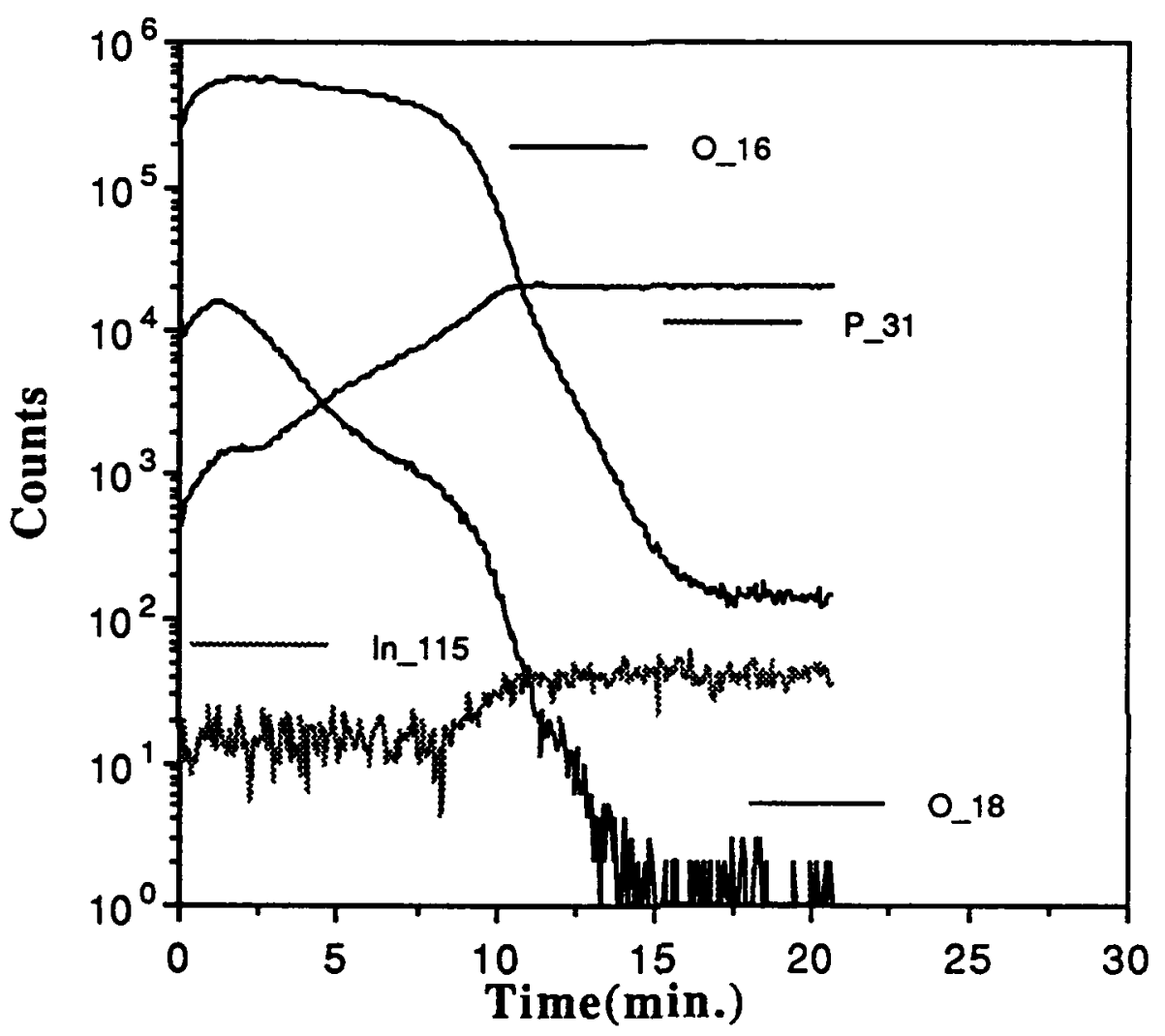

Fig. 26 


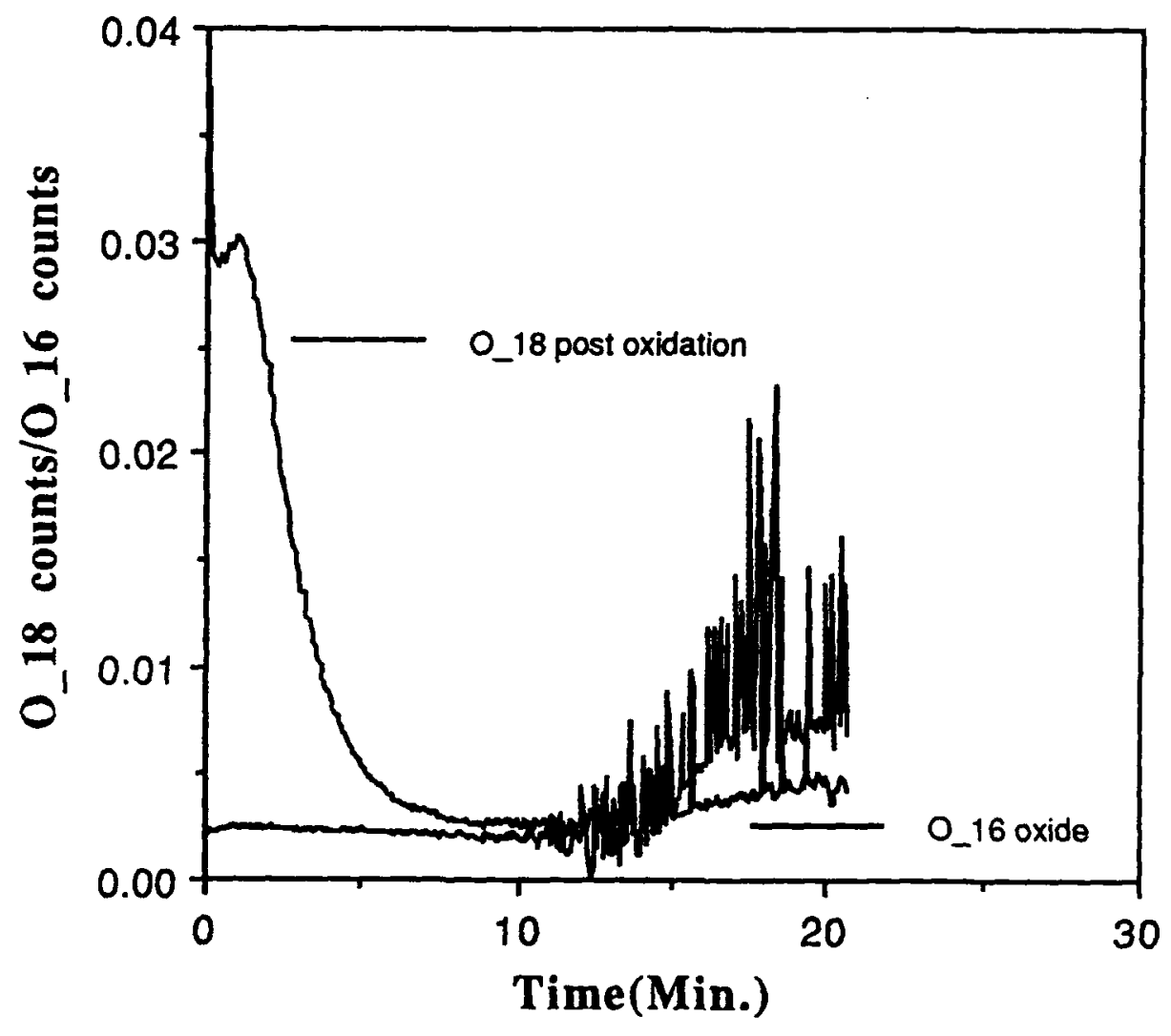

Fig. 3 


\section{InP THERMAL OXIDATION}

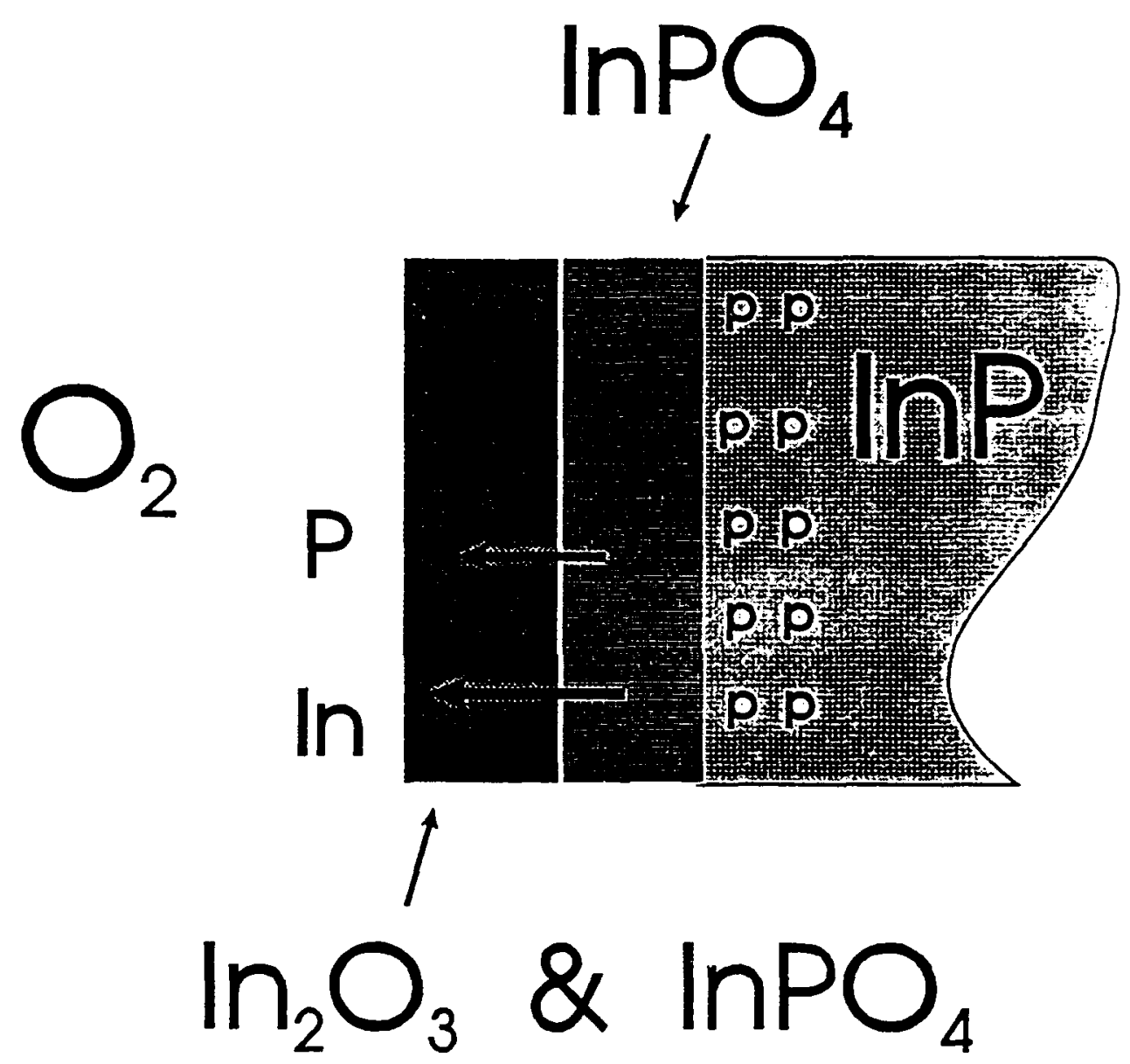

